\title{
Extrapleural pneumonectomy versus pleurectomy/ decortication in the surgical management of malignant pleural mesothelioma: Results in 663 patients
}

\author{
Raja M. Flores, MD, ${ }^{a}$ Harvey I. Pass, MD, ${ }^{d}$ Venkatraman E. Seshan, PhD, ${ }^{\text {b }}$ Joseph Dycoco, BA, ${ }^{a}$ \\ Maureen Zakowski, MD, ${ }^{\mathrm{c}}$ Michele Carbone, MD, ${ }^{\mathrm{e}}$ Manjit S. Bains, MD, ${ }^{\mathrm{a}}$ and Valerie W. Rusch, MD ${ }^{\mathrm{a}}$
}

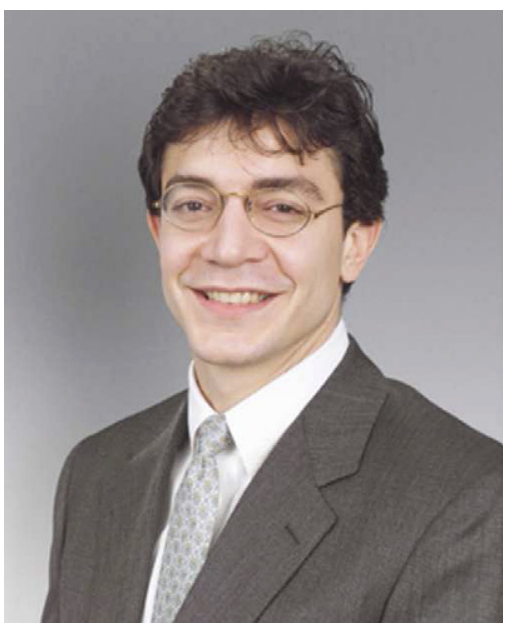

Dr Flores

Supplemental material is available online.

From the Thoracic Service, Department of Surgery, ${ }^{a}$ Biostatistics Service, Department of Epidemiology and Biostatistics, ${ }^{\text {b }}$ Department of Pathology, ${ }^{\mathrm{c}}$ Memorial SloanKettering Cancer Center, New York, NY; Department of Cardiothoracic Surgery, New York University Medical Center, ${ }^{\mathrm{d}}$ New York, NY; and Department of Pathology, University of Hawaii, ${ }^{\mathrm{e}}$ Honolulu, Hawaii.

This study was presented at the plenary session at the 2007 AATS Meeting.

Dr Pass reports consulting fees from GlaxoSmithKline and Astra Zeneca.

Received for publication May 3, 2007; revisions received Sept 13, 2007; accepted for publication Oct 22, 2007.

Address for reprints: Raja M. Flores, MD, Thoracic Service, Department of Surgery, Memorial Sloan-Kettering Cancer Center, 1275 York Avenue, Room C-879, New York, NY 10021 (E-mail: floresı@mskcc.org).

J Thorac Cardiovasc Surg 2008;135:620-6 $0022-5223 / \$ 34.00$

Copyright $(2008$ by The American Association for Thoracic Surgery

doi:10.1016/j.jtcvs.2007.10.054
Objective: The optimal procedure for resection of malignant pleural mesothelioma is controversial, partly because previous analyses include small numbers of patients. We performed a multi-institutional study to increase statistical power to detect significant differences in outcome between extrapleural pneumonectomy and pleurectomy/ decortication.

Methods: Patients with malignant pleural mesothelioma who underwent extrapleural pneumonectomy or pleurectomy/decortication at 3 institutions were identified. Survival and prognostic factors were analyzed by the Kaplan-Meier method, log-rank test, and Cox proportional hazards analysis.

Results: From 1990 to 2006, 663 consecutive patients (538 men and 125 women) underwent resection. The median age was 63 years (range, 26-93 years). The operative mortality was $7 \%$ for extrapleural pneumonectomy $(n=27 / 385)$ and $4 \%$ for pleurectomy/decortication $(n=13 / 278)$. Significant survival differences were seen for American Joint Committee on Cancer stages 1 to $4(P<.001)$, epithelioid versus non-epithelioid histology $(P<.001)$, extrapleural pneumonectomy versus pleurectomy/decortication $(P<.001)$, multimodality therapy versus surgery alone $(P<$ $.001)$, and gender $(P<.001)$. Multivariate analysis demonstrated a hazard rate of 1.4 for extrapleural pneumonectomy $(P<.001)$ controlling for stage, histology, gender, and multimodality therapy.

Conclusion: Patients who underwent pleurectomy/decortication had a better survival than those who underwent extrapleural pneumonectomy; however, the reasons are multifactorial and subject to selection bias. At present, the choice of resection should be tailored to the extent of disease, patient comorbidities, and type of multimodality therapy planned.

$\mathrm{T}$ The role of surgical resection, especially extrapleural pneumonectomy (EPP), in the management of malignant pleural mesothelioma (MPM) is controversial. EPP usually involves an en bloc resection of lung, pleura, pericardium, and diaphragm, whereas pleurectomy/decortication (P/D) involves resection of the parietal and visceral pleurae, pericardium, and diaphragm when necessary, but spares the lung. The goal of surgery is to remove all gross disease, but a complete resection (R0) with surgery alone is theoretically unattainable because of the inability to eradicate residual microscopic disease regardless of whether an EPP or P/D is performed. Therefore, treatment has focused on surgery in combination with radiation and/or chemotherapy in a multimodality setting.

The majority of studies have included exclusively either P/D or EPP in conjunction with preoperative or postoperative chemotherapy, intrathoracic chemotherapy, postoperative external beam radiotherapy, intensity-modulated radiation therapy, intraoperative radiotherapy, brachytherapy, photodynamic therapy, and a number of 


\section{Abbreviations and Acronyms \\ $\mathrm{EPP}=$ extrapleural pneumonectomy \\ $\mathrm{MPM}=$ malignant pleural mesothelioma \\ $\mathrm{P} / \mathrm{D}=$ pleurectomy/decortication}

other novel adjuvants. ${ }^{1-11}$ However, the decision to perform either EPP or P/D in multimodality studies is based predominantly on surgeon bias rather than scientific data.

Several studies have chosen end points, such as time to progression and patterns of recurrence, to justify the preferred procedure because the numbers are too small to demonstrate statistically significant differences in survival. ${ }^{12-14}$ However, these end points are fraught with inaccuracy because the follow-up practices, definitions of progression of disease, and ways of documenting recurrence vary greatly. Thus, rates of progression-free survival may differ considerably from overall survival. Therefore, this study was undertaken to investigate the outcomes of EPP and P/D with overall survival as the primary end point.

\section{Materials and Methods}

All information on patients with biopsy-proven MPM who underwent EPP and P/D between 1990 and 2006 was obtained and analyzed under institutional review board approval at the Memorial Sloan-Kettering Cancer Center, National Cancer Institute, and Karamanos Cancer Institute. A common variable database was created. Pathologic diagnosis was based on histology, immunohistochemical analysis, and, when indicated, electron microscopy. Clinical data were obtained from institutional databases, and variables recorded included age, gender, histologic subtype, laterality, stage, asbestos exposure history, surgical procedure, and multimodality treatment. Staging was performed using the sixth edition of the AJCC Cancer Staging Handbook. ${ }^{15}$ Pathologic stage was based on the pathologist's evaluation of the resected specimen and the surgeon's intraoperative findings. All patients were followed until the date of death or the date of last follow-up if still alive. Dates of death were verified through the Social Security Death Index and personal telephone communications.

Treatment selection was based primarily on the tumor stage, patients' overall medical condition, and requirements of several prospective clinical trials performed during this time period. Operative intervention was recommended to patients with tumor localized to the hemithorax by computed tomography scan and adequate cardiopulmonary function testing. Routine mediastinoscopy and magnetic resonance imaging were not performed. Positron emission tomography has only recently been used for clinical staging. EPP was defined as an en bloc resection of the pleura, lung, ipsilateral diaphragm, and pericardium. P/D removed tumor with the parietal and visceral pleurae and pericardium and/or diaphragm when necessary without removing the entire underlying lung. In patients not participating in protocols that mandated either EPP or $\mathrm{P} / \mathrm{D}$, the decision to perform an EPP or P/D was based on intraoperative findings, tumor stage, patients' medical condition, and surgeons' intraoperative judgment about which procedure would permit resection of all gross tumor. The decision to perform chemotherapy or radiation was based on enrollment in a clinical trial. The total radiation dose and method of administration was dependent on whether an EPP or a P/D had been performed. ${ }^{16,17}$ When a patient could not participate in a clinical trial, therapy was administered according to protocol guidelines.

\section{Statistical Methods}

Comparison of proportions of prognostic variables in EPP and P/D were assessed by the Pearson chi-square test. Operative mortality included all patients who died within 30 days of surgery or during the same hospitalization. Survival was calculated from the date of surgery until the date of death or the date of last follow-up. Survival and prognostic factors were analyzed by the Kaplan-Meier method, and the log-rank test was used to assess statistical significance. A Cox proportional hazard analysis was used to assess the joint influences of predictors on survival. Insignificant variables were then excluded from the analysis using a stepwise procedure, thus yielding the final model. The Stata 8 (Stata Corp, College Station, Tex) statistical package was used.

\section{Results}

A total of 663 consecutive patients underwent surgical resection by either EPP or P/D (Memorial Sloan-Kettering Cancer Center, $n=448$; National Cancer Institute, $n=96$; Karamanos Cancer Institute, $\mathrm{n}=119)$. The clinical characteristics are outlined in Table E1 and were typical of patients with MPM. Patients were predominantly male and often gave a history of asbestos exposure. Most tumors were of epithelioid histology and were stages II or III at diagnosis. Approximately $60 \%$ of patients underwent EPP. Operative mortality was $7 \%$ for EPP $(n=27 / 385)$ and $4 \%$ for $P / D(n=13 / 278)$. A comparison of the distribution of prognostic variables between patients undergoing EPP and P/D are presented in Table 1. P/D had a significantly greater proportion of patients who were several years older with early stage tumors, whereas patients undergoing EPP were more likely to receive multimodality therapy, have a higher proportion of epithelioid tumors, and have a greater frequency of asbestos exposure. Postoperative complications recorded according to the Common Terminology Criteria for Adverse Events version 3.0 grading system are outlined in Table E2. It was not surprising that the most common adverse events among patients undergoing EPP were atrial arrhythmias and respiratory complications. Severe or life-threatening (grades 3-5) respiratory complications occurred in $10 \%$ of patients undergoing EPP. Serious respiratory complications were less frequent after $\mathrm{P} / \mathrm{D}$, occurring in $6.4 \%$ of patients, but were still the most common adverse event. Patterns of recurrence are outlined in Table 2.

With a median follow-up of 17 months, the median survival of all patients in this study was 14 months. Of the 663 patients, only 97 were censored, 47 of 97 (48.5\%) who underwent P/D and 50 of $97(51.5 \%)$ who underwent EPP. The overall survival at 5 years for all patients was $12 \%$, and the median survival was 38 months for stage I, 19 months 
TABLE 1. Comparison of prognostic variables among patients undergoing extrapleural pneumonectomy and pleurectomy/decortication

\begin{tabular}{lccr}
\hline & EPP $(\mathbf{n}=\mathbf{3 8 5})$ & P/D $(\mathbf{n}=\mathbf{2 7 8})$ & $\boldsymbol{P}$ value \\
\hline Age (mean) & $60 \mathrm{y}$ & $63 \mathrm{y}$ & $<.001$ \\
Male gender & $316(82 \%)$ & $220(79 \%)$ & .267 \\
Epithelioid histology & $269(69 \%)$ & $178(64 \%)$ & .090 \\
Early stage (I + II) & $96(25 \%)$ & $98(35 \%)$ & $<.001$ \\
Asbestos exposure & $231(60 \%)$ & $149(54 \%)$ & .080 \\
Laterality (right) & $217(56 \%)$ & $173(62 \%)$ & .156 \\
Multimodality therapy & $266(69 \%)$ & $161(58 \%)$ & .002
\end{tabular}

$E P P$, Extrapleural pneumonectomy; $P / D$, pleurectomy/decortication.

for stage II, 11 months for stage III, and 7 months for stage IV tumors (Figure E1). Univariate analyses showed that tumor histologic subtype and stage, both commonly accepted prognostic variables, were associated with highly significant differences in survival, both with $P$ values of less than .001 (Figures 1 and 2$)$. Female gender $(P<.001)$ and multimodality treatment $(P<.001)$ were significantly associated with improved survival. History of asbestos exposure demonstrated a slightly improved survival for patients without asbestos exposure $(P=.06)$. Laterality and surgeon were not significant.

By univariate analysis, EPP was associated with a significantly worse survival than P/D $(P<.001)$ (Figure 3$)$, even when operative deaths were excluded. An analysis of surgical procedure in relationship to American Joint Committee on Cancer tumor stage was performed to identify differences in survival in favor of EPP versus P/D. There was no statistical difference in survival by procedure at any individual tumor stage (Figures 4-7). Only 14 patients underwent EPP with stage IV disease (usually T4 tumors) with a median survival of 4 months.

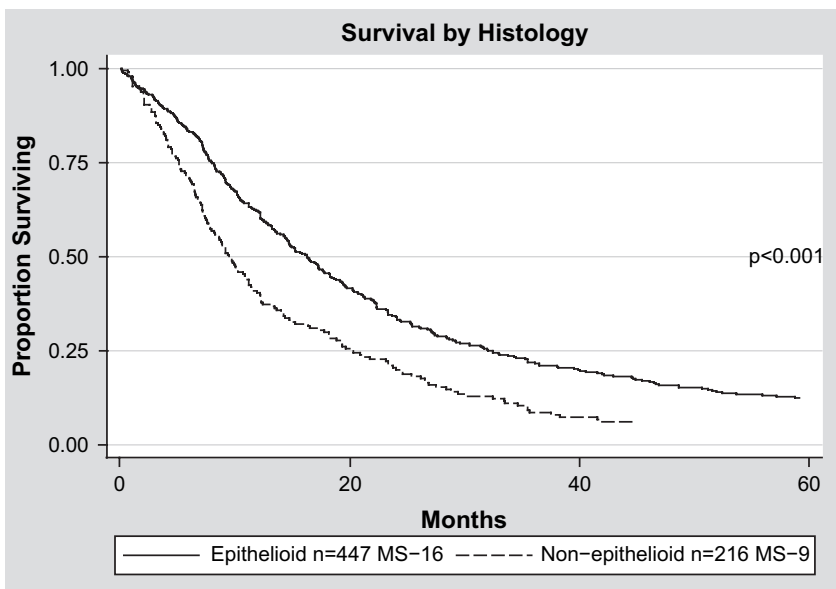

Figure 1. Overall survival of epithelioid versus non-epithelioid tumor, by univariate analysis.

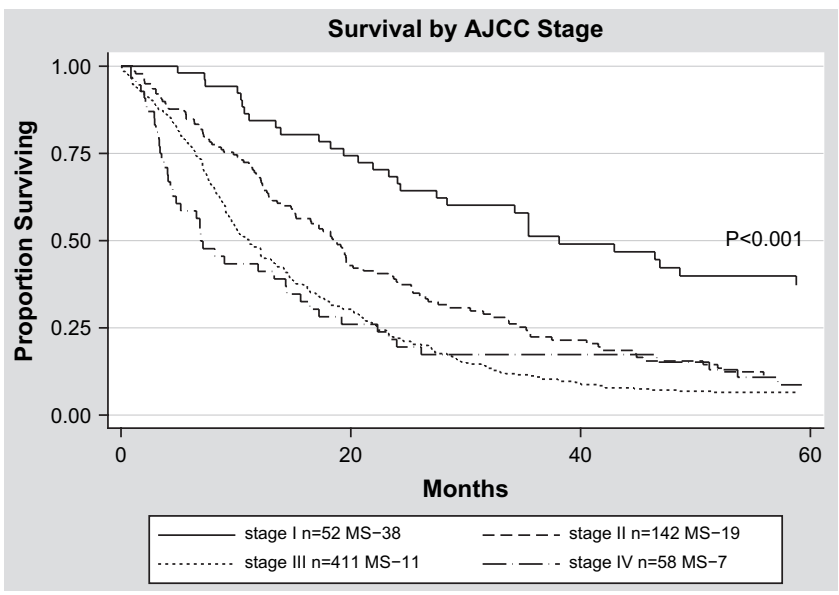

Figure 2. Overall survival by American Joint Committee on Cancer stage, by univariate analysis. AJCC, American Joint Committee on Cancer.

In an analysis grouping larger numbers of patients by early stage (stages I and II), there was also no significant difference between EPP ( $\mathrm{n}=96 ; 19$ months) and P/D $(\mathrm{n}=98 ; 23$ months, $P=.07$ ), even when operative deaths were excluded; there was no significant difference by late stage disease (stages III and IV, data not shown). In a multivariable analysis by Cox proportional hazards model that controlled for histology, stage, gender, and multimodality therapy, EPP had a higher hazard ratio of 1.4 compared with P/D $(P<.001)($ Table 3$)$.

\section{Discussion}

The treatment of MPM remains controversial but has evolved considerably during the past 16 years of this study. Advances in the management of MPM include easier and more accurate

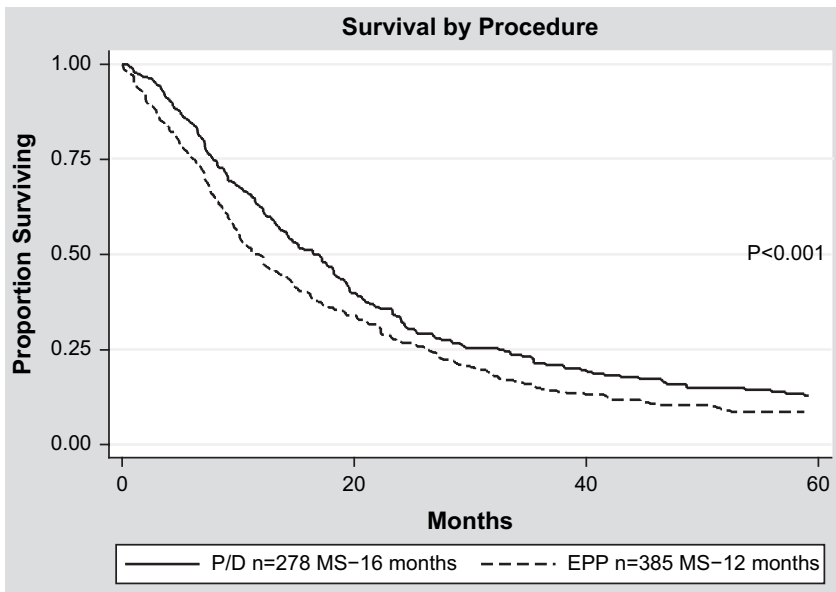

Figure 3. Overall survival of EPP versus $P / D$, by univariate analysis. EPP, Extrapleural pneumonectomy; $P / D$, pleurectomy/ decortication. 


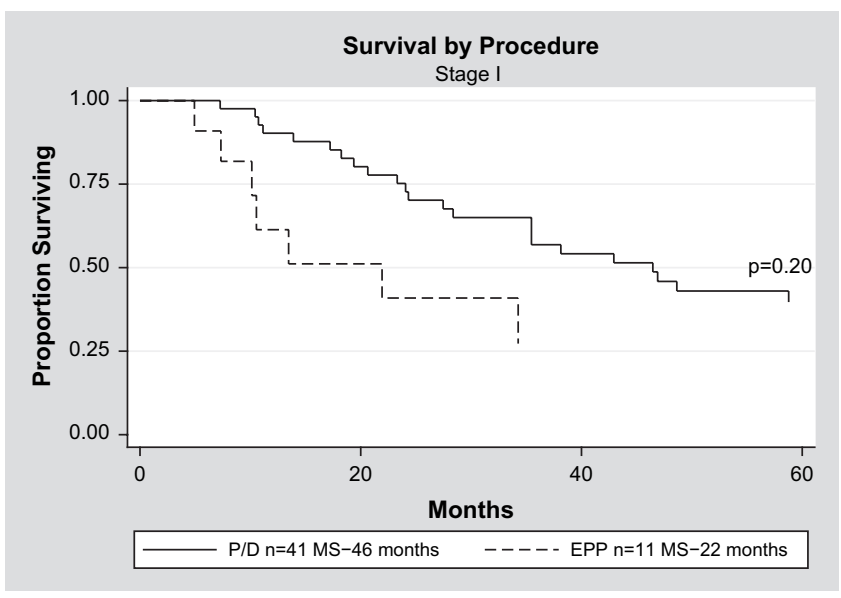

Figure 4. Overall survival of EPP versus $P / D$ for patients with stage I. EPP, Extrapleural pneumonectomy; $P / D$, pleurectomy/ decortication.

methods of pathologic diagnosis, improved methods of staging and selecting patients for surgery, a significant decrease in operative mortality especially for EPP, marked improvements in local control with combined resection and adjuvant radiotherapy, and better systemic therapies ${ }^{3,6,18-24}$ These changes have led to wide variations and considerable controversy in the use of EPP or P/D for resection of MPM. Controversy over EPP and P/D focuses on their relative merits with respect to operative risk, ability to remove all gross tumor, and options for adjuvant therapy. Proponents of EPP believe that it more frequently allows a complete removal of all gross tumor (R0/R1 resection), with increasingly acceptable rates of morbidity and mortality, and facilitates the administration of postoperative high-dose hemithoracic radiation, which in

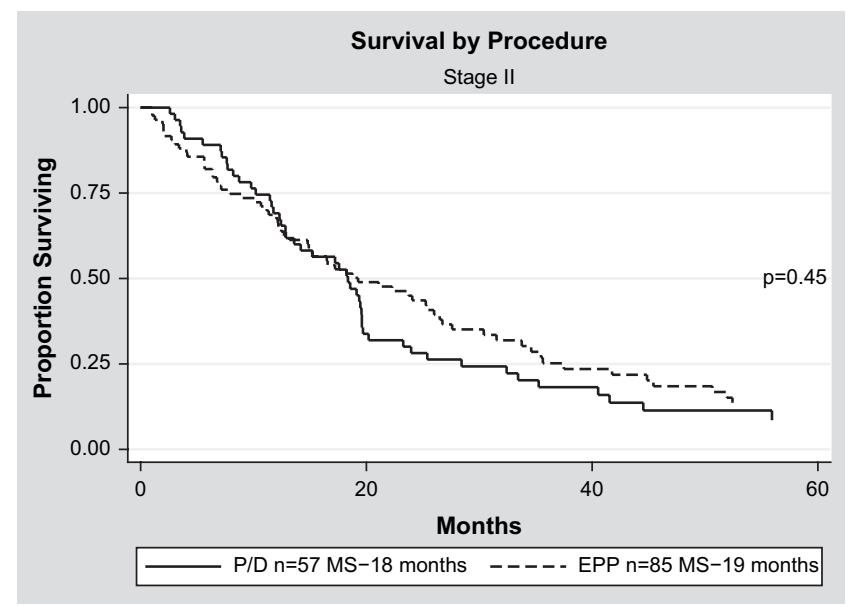

Figure 5. Overall survival of EPP versus $P / D$ for patients with stage II. EPP, Extrapleural pneumonectomy; $P / D$, pleurectomy/ decortication.

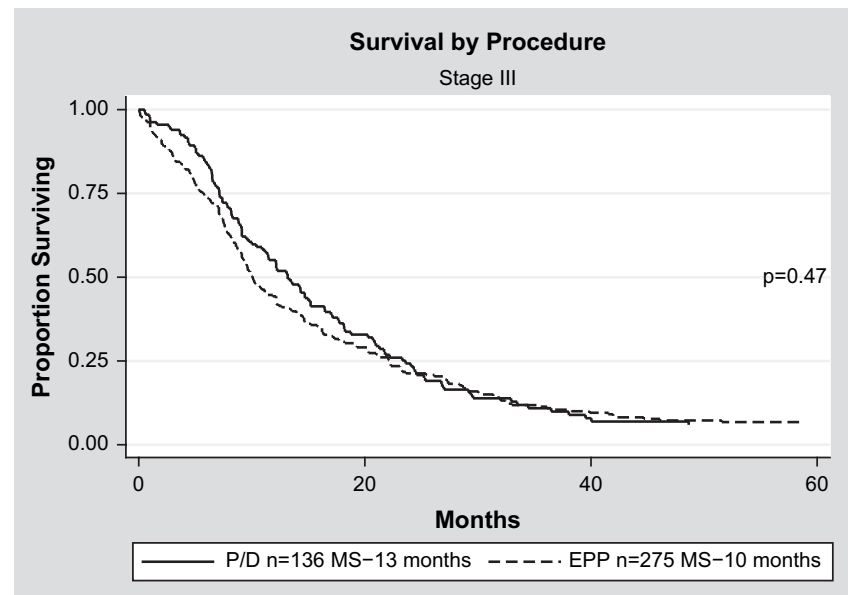

Figure 6. Overall survival of EPP versus $P / D$ for patients with stage III. EPP, Extrapleural pneumonectomy; $P / D$, pleurectomy/ decortication.

turns provides excellent local control. ${ }^{6}$ Proponents of P/D believe that it provides adequate cytoreduction, especially for patients with earlier stage tumors, is associated with a lower morbidity and mortality than EPP, and is an effective part of a multimodality treatment program in conjunction with therapies such as photodynamic therapy, intrapleural or systemic chemotherapy, and intensity-modulated radiation therapy. ${ }^{1,2,4-6,10,11}$

Our results in this study reflect all of the pros and cons and the controversies surrounding the use of EPP and P/D. In a patient population who are typical for MPM (given age, gender, tumor stage, and histology), our decision to perform an EPP or $\mathrm{P} / \mathrm{D}$ was based on a combination of factors, including patient operative risk, technical ability to remove all gross

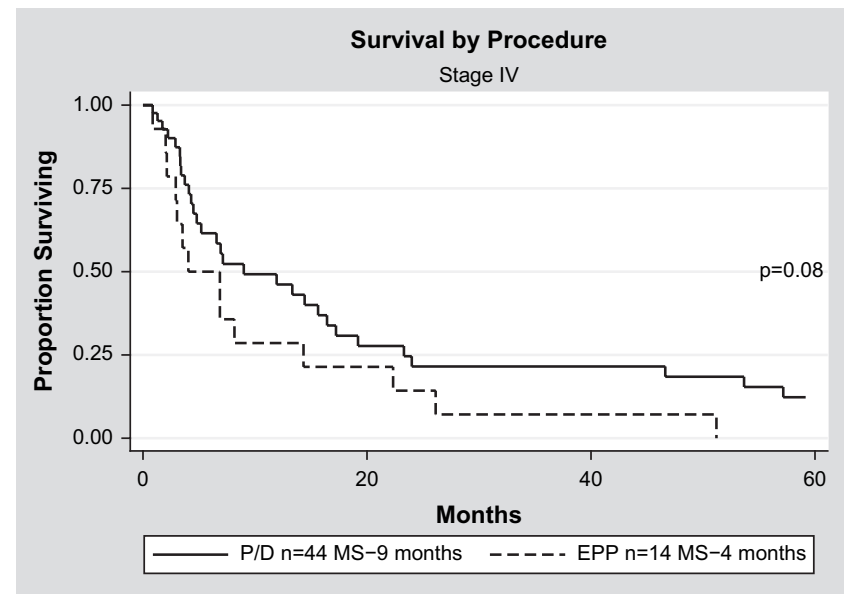

Figure 7. Overall survival of EPP versus $P / D$ for patients with stage IV. EPP, Extrapleural pneumonectomy; $P / D$, pleurectomy/ decortication. 
TABLE 2. Site of first recurrence after extrapleural pneumonectomy versus pleurectomy/decortication

\begin{tabular}{lcc}
\hline & EPP (n = 219) $\mathbf{n}(\%)$ & P/D (n = 133) n (\%) \\
\hline Local recurrences & $73(33 \%)$ & $86(65 \%)$ \\
Ipsilateral chest & $68(31 \%)$ & $84(63 \%)$ \\
Pericardium & $5(2 \%)$ & $2(2 \%)$ \\
Distant recurrences & $146(66 \%)$ & $47(35 \%)$ \\
Contralateral lung/pleura & $49(22 \%)$ & $14(11 \%)$ \\
Peritoneum & $57(26 \%)$ & $24(18 \%)$ \\
Peritoneum + chest & $17(8 \%)$ & 1 \\
Abdominal viscera & $12(5 \%)$ & $4(3 \%)$ \\
Bone & $7(3 \%)$ & - \\
Brain & 1 & 1 \\
Cutaneous (distant) & 1 & 1 \\
Other & 2 & $2(2 \%)$ \\
\hline
\end{tabular}

$E P P$, Extrapleural pneumonectomy; $P / D$, pleurectomy/decortication.

disease, and participation in a series of clinical trials that mandated performing either one operation or the other. Although our study is retrospective, it benefits from being multicenter and including a larger number of patients than other surgical series, and therefore has a greater statistical power to identify potential survival differences between EPP and P/D. Our results confirm previous smaller studies with respect to the lower mortality of $\mathrm{P} / \mathrm{D}$, differences in postoperative adverse events, and patterns of relapse. Patients who undergo EPP and adjuvant therapy, particularly highdose hemithoracic radiation, relapse predominantly in distant sites, whereas after P/D disease progression occurs predominantly locally in the ipsilateral hemithorax. ${ }^{1,2,4-6,16}$ Any clinician who treats patients with MPM is well aware of these differences in disease progression that lead to notable differences in patient symptoms during the latter phases of their disease. Local disease progression after P/D leads to death from worsening restrictive lung disease, intractable chest pain, and respiratory failure. Distant disease progression, usually after EPP, manifests most frequently with dyspnea from a contralateral pleural effusion, ascites, or both.

The relative impact of EPP and P/D on overall survival is less clear. The results of our univariate analyses suggesting a strong survival benefit for P/D become only marginally

TABLE 3. Multivariate analysis of prognostic variables that were significant by univariate analysis

\begin{tabular}{lccc}
\hline & Hazard ratio & Confidence interval & $\boldsymbol{P}$ value \\
\hline Age & 1.0 & $(1.01-1.02)$ & $P<.001$ \\
Female gender & 1.3 & $(1.05-1.64)$ & $P=.02$ \\
EPP & 1.4 & $(1.18-1.69)$ & $P<.001$ \\
Non-epithelioid & 1.3 & $(1.11-1.60)$ & $P<.001$ \\
Stage III/IV & 1.4 & $(1.28-1.55)$ & $P<.001$ \\
Multimodality therapy & .45 & $(0.38-0.54)$ & $P<.001$ \\
\hline
\end{tabular}

$E P P$, Extrapleural pneumonectomy. significant (hazard ratio $=1.4$ ) when considered in a multivariable analysis that accounts for other important variables, such as tumor stage, histology, gender, and multimodality treatment. This emphasizes the importance of considering surgical data within the context of known prognostic factors. Viewed from the most nihilistic perspective, these results could be interpreted as indicating that neither approach to resection influences overall survival that is primarily dependent on tumor histology, stage, nonsurgical therapy, and various still undefined biological factors. Previous series and clinical trials argue against this perspective, ${ }^{1-3,6}$ but ultimately this question may be answered by a randomized clinical trial currently under way in the United Kingdom that addresses the survival benefit of EPP relative to nonsurgical therapy. Viewed from another perspective, our results could be interpreted as emphasizing the lack of truly effective systemic therapy for MPM. For instance, patients who underwent EPP who receive adjuvant hemithoracic radiation have a low risk of local recurrence but currently have no available systemic therapy that significantly reduces the risk of distant metastases. ${ }^{1,2,6,14}$ No matter what the efficacy of EPP or P/D in removing gross tumor, the lack of highly effective adjuvant therapy for both of these operations leads to similar results in terms of overall survival. By contrast, locally advanced ovarian cancer, which is currently managed with a combination of vigorous surgical cytoreduction and adjuvant chemotherapy, is potentially curable, not only because of the proven benefits of resection but also because of the effectiveness of current chemotherapy for that disease.

Our study suffers from a lack of comorbidity data. Although patients undergoing EPP are more likely to have less comorbid disease than those undergoing $\mathrm{P} / \mathrm{D}$, this bias would tend to falsely inflate survival results in the EPP group. Selection bias plays a large role in determining who receives $\mathrm{EPP}$ or $\mathrm{P} / \mathrm{D}$ on the basis of intraoperative findings. There are probably unmeasurable differences in the extent of disease not accounted for in the staging system that may make the tumor stage in patients undergoing EPP even more advanced within the same stage, thus falsely favoring survival in the $\mathrm{P} /$ $\mathrm{D}$ group. In addition, the ability of patients to undergo adjuvant therapy is biased based on their postoperative functional status, which, per se, would account for the differences in survival between patients undergoing multimodality therapy versus patients undergoing surgery alone. This finding would tend to favor EPP because $69 \%$ of patients receiving EPP underwent multimodality therapy compared with $58 \%$ of patients receiving P/D. Regardless of controlling for all known biases, the data by its retrospective nature are limited and the influence of unknown confounding variables cannot be accounted for short of a randomized trial.

\section{Conclusions}

Our study emphasizes the similarities in outcome after EPP or P/D for MPM in a multicenter setting and do not allow 
us to advocate clearly for either one or the other surgical approach at the current time. Pending the development of more effective multimodality therapy, careful patient selection for both EPP and P/D on the basis of the cardiopulmonary function, extent of the tumor, and ability to resect all gross disease remains key to offering patients good treatment with acceptable risk. Given the limitations that EPP and P/D impose on the options for adjuvant therapy, we believe that the choice of surgical procedure must also take into account for each patient a multidisciplinary decision about the use of nonsurgical therapies. Finally, our results emphasize the need for additional well-designed prospective trials that address the impact of these surgical procedures on outcome and patterns of relapse within the context of multimodality therapy.

\section{References}

1. Flores RM, Krug LM, Rosenzweig KE, Venkatraman E, Vincent A, Heelan R, et al. Induction chemotherapy, extrapleural pneumonectomy, and postoperative high-dose radiotherapy for locally advanced malignant pleural mesothelioma: a phase II trial. J Thorac Oncol. 2006;1: 289-95.

2. Weder W, Kestenholz P, Taverna C, Bodis S, Lardinois D, Jerman M, et al. Neoadjuvant chemotherapy followed by extrapleural pneumonectomy in malignant pleural mesothelioma. J Clin Oncol. 2004;22:3451-7.

3. Sugarbaker DJ, Flores RM, Jaklitsch MT, Richards WG, Strauss GM, Corson JM, et al. Resection margins, extrapleural nodal status, and cell type determine postoperative long-term survival in trimodality therapy of malignant pleural mesothelioma: results of 183 patients. J Thorac Cardiovasc Surg. 1999;117:54-65.

4. Rusch VW, Saltz L, Venkatraman E, Ginsberg R, McCormack P, Burt M, et al. A phase II trial of pleurectomy/decortication followed by intrapleural and systemic chemotherapy for malignant pleural mesothelioma. J Clin Oncol. 1994;12:1156-63.

5. Richards WG, Zellos L, Bueno R, Jaklitsch MT, Jänne PA, Chirieac LR, et al. Phase I to II study of pleurectomy/decortication and intraoperative intracavitary hyperthermic cisplatin lavage for mesothelioma. J Clin Oncol. 2006;24:1561-7.

6. Rusch VW, Rosenzweig K, Venkatraman E, Leon L, Raben A, Harrison L, et al. A Phase II trial of surgical resection and adjuvant high dose hemithoracic radiation for malignant pleural mesothelioma. J Thorac Cardiovasc Surg. 2001;122:788-95.

7. Lee TT, Everett DL, Shu H-KG, Jahan TM, Roach M III, Speight JL, et al. Radical pleurectomy/decortication and intraoperative radiotherapy followed by conformal radiation with or without chemotherapy for malignant pleural mesothelioma. J Thorac Cardiovasc Surg. 2002; 124:1183-9.

8. Hilaris BS, Dattatreyudu N, Kwong E, Kutcher GJ, Martini N. Pleurectomy and intraoperative brachytherapy and postoperative radiation in the treatment of malignant pleural mesothelioma. Int J Radiat Oncol Biol Phys. 1984;10:325-31.

9. McCormack PM, Nagasaki F, Hilaris BS, Martini N. Surgical treatment of pleural mesothelioma. $J$ Thorac Cardiovasc Surg. 1982;84:834-42.

10. Pass HI, Temeck BK, Kranda K, Thomas G, Russo A, Smith P, et al. Phase III randomized trial of surgery with or without intraoperative photodynamic therapy and postoperative immunochemotherapy for malignant pleural mesothelioma. Ann Surg Oncol. 1997;4:628-33.

11. Lu C, Perez-Soler R, Piperdi B, Walsh GL, Swisher SG, Smythe WR, et al. Phase II study of a liposome-entrapped cisplatin analog (L-NDDP) administered intrapleurally and pathologic response rates in patients with malignant pleural mesothelioma. J Clin Oncol. 2005;23:3495-501.

12. Allen KB, Faber LP, Warren WH. Malignant pleural mesothelioma. Extrapleural pneumonectomy and pleurectomy. Chest Surg Clin N Am. 1994;4:113-26.

13. Rusch VW, Piantadosi S, Holmes EC. The role of extrapleural pneumonectomy in malignant pleural mesothelioma. J Thorac Cardiovasc Surg. $1991 ; 102: 1-9$
14. Stewart DJ, Martin-Ucar A, Pilling JE, Edwards JG, O'Byrne KJ, Waller DA. The effect of extent of local resection on patterns of disease progression in malignant pleural mesothelioma. Ann Thorac Surg. 2004; 78:245-52.

15. American Joint Committee on Cancer. In: Greene FL, Page DL, Fleming ID, Fritz AG, Balch CM, Haller DG, et al., editors. AJCC Cancer Staging Handbook. 6th ed. New York: Springer-Verlag; 2002.

16. Yajnik S, Rosenzweig KE, Mychalczak B, Krug L, Flores R, Hong L, et al. Hemithoracic radiation after extrapleural pneumonectomy for malignant pleural mesothelioma. Int J Radiat Oncol Biol Phys. 2003; $56: 1319-26$

17. Gupta V, Mychalczak B, Krug L, Flores R, Bains M, Rusch VW, et al. Hemithoracic radiation therapy after pleurectomy/decortication for malignant pleural mesothelioma. Int J Radiat Oncol Biol Phys. 2005; 63:1045-52.

18. Battifora H, McCaughey WTE. Tumors of the Cardiovascular System. Atlas of Tumor Pathology. Washington, DC: Armed Forces Institute of Pathology; 2003.

19. Flores RM, Akhurst T, Gonen M, Larson SM, Rusch VW. Positron emission tomography defines metastatic disease but not locoregional disease in patients with malignant pleural mesothelioma. J Thorac Cardiovasc Surg. 2003;126:11-6.

20. Flores RM, Akhurst T, Gonen M, Zakowski M, Dycoco J, Larson SM, et al. Positron emission tomography (PET) predicts survival in malignant pleural mesothelioma (MPM). J Thorac Cardiovasc Surg. 2006;132:763-8.

21. Rusch VW, Venkatraman ES. Important prognostic factors in patients with malignant pleural mesothelioma, managed surgically. Ann Thorac Surg. 1999;68:1799-804.

22. Byrne MJ, Davidson JA, Musk AW, Dewar J, van Hazel G, Buck M, et al. Cisplatin and gemcitabine treatment for malignant mesothelioma: a phase II study. J Clin Oncol. 1999;17:25-30.

23. Van Meerbeeck JP, Gaafar R, Manegold C, van Klaveren RJ, van Marck EA, Vincent M, et al. Randomized phase III study of cisplatin with or without raltitrexed in patients with malignant pleural mesothelioma: an intergroup study of the European Organisation for Research and Treatment of Cancer Lung Cancer Group and the National Cancer Institute of Canada. J Clin Oncol. 2005;23:6881-9.

24. Vogelzang NJ, Rusthoven J, Symanowski J, Denham C, Kaukel E, Ruffie P, et al. Phase III study of pemetrexed in combination with cisplatin versus cisplatin alone in patients with malignant pleural mesothelioma. J Clin Oncol. 2003;21:2636-44.

\section{Discussion}

Dr D. Sugarbaker (Boston, Mass). It now seems that aggressive surgical resection by EPP or P/D has an established role for treating MPM particularly, and I think exclusively, in patients whose disease is confined to the hemithorax. As you pointed out, there continues to be controversy and, I would suggest, confusion over whether EPP or $\mathrm{P} / \mathrm{D}$ is a better operation. I have argued previously that achieving a macroscopic complete resection (MCR) is the goal, as you have suggested here as well, of mesothelioma surgery, whichever procedure is used.

When comparing outcome for these procedures, one needs to be mindful of the other prognostic factors that you have reviewed here that affect survival. The principal factor, of course, is cell type, with pure epithelial tumors behaving better in all published series than the mixed or sarcomatous lesions. In addition, N2 node status, as reported by our group at the Brigham, and disease bulk, as reported by Harvey Pass, are significant prognostic factors. Particularly when one considers bulk disease, as you have suggested, EPP is many, many times the only operation where an R0 or MCR can be achieved. I would therefore urge cautious interpretation of survival comparisons between patients receiving P/D or EPP who do not at least demonstrate a balance in these important prognostic factors. 
In addition, I think your presentation highlights what I have suggested, that non-epithelial MPM represents a distinct clinical entity that should be examined and reported separately from epithelial MPM. These subgroups of patients are different, their clinical course is dramatically different, and it may be that their therapies eventually become diverse as well.

So I have a couple of questions for you, Dr Flores. I think you would agree that the appropriate operation in the setting of MPM is the one most likely to result in an MCR. In many cases this determination is made at thoracotomy, and appropriately, early disease is commonly resected by P/D when it appears that an MCR can be achieved. As you pointed out in your study, $15 \%$ of the patients receiving P/D had stage I compared with only $3 \%$ of the patients receiving EPP. Bulky disease, which has been identified by Harvey Pass as an indicator of poor prognosis, is more likely to be approached by EPP in terms of obtaining an MCR, and it remains unclear whether the type of surgical resection can actually affect the prognosis when bulk disease has driven metastatic deposits, as you have also shown here. Could these appropriate clinical differences in terms of bulk and cell type account for the survival difference you observed in the 2 procedures?

Dr Flores. Absolutely. I don't think that these 2 procedures are interchangeable. You don't know what procedure you are going to do until you get in there at the time of thoracotomy. That is why any comparison that says the outcome is the same, why not just do a P/D because you are sparing the lung? The point is if you have experience in mesothelioma surgery, you realize you can't get most of them out without doing an EPP. It is an intraoperative decision. That is why there were so few EPP procedures in the patients with stage I, because you just can't compare it. It depends more on the $\mathrm{T}$ stage. There are some pleurectomies in the stage III disease, and those are usually patients who had N2 disease. If you have big bulky tumor, you need an EPP, period.

Dr Sugarbaker. Given the prognostic importance of N2 that we have demonstrated at the Brigham and your group at Memorial has also demonstrated, at the Brigham now we are routinely performing mediastinoscopy on patients presenting with MPM. Could you comment on whether you have used this and on what you believe is the most effective adjuvant therapy? Because MCR by either procedure is the surgeon's goal, how do we complete the therapy? What are your current thoughts about what the best adjuvant treatment is?

Dr Flores. That is a point of controversy as well, what is the best type of adjuvant therapy, and that definitely depends on the type of procedure that you perform. If you perform an EPP and you remove all gross disease, you don't have the lung in place, so you can theoretically really crank up the radiation. At our institution we go up to 5400 rads to really cook that chest to get the residual macroscopic disease. Now, those are the best results that we have obtained in achieving local control.
For $\mathrm{P} / \mathrm{D}$, some have tried intraoperative radiotherapy, others have tried intrapleural chemotherapy. The type of resection that you perform dictates your adjuvant therapy.

Dr M. Krasna (Towson, Md). Your group, and ours, took part in a prospective trial using trimodality therapy for treating patients with mesothelioma. I understand the comparison if surgery alone was all that we are advocating. However, there are now good data that the combination of at least adjuvant and perhaps neoadjuvant therapy, including, for instance, chemotherapy with pemetrexed (Alimta, Eli Lilly and Co, Indianapolis, Ind) and/or cisplatinum, might actually have a better result both in terms of survival and complete resection. Would you comment on specifically the question of an extrapleural versus a decortication in the context of patients who receive neoadjuvant therapy?

Dr Flores. I think as far as multimodality therapy is concerned, when you look at these patients in this study and you compare those who had multimodality therapy versus those who did not, there is a survival benefit for those who had multimodality therapy. Of course, that is a very biased group, because the patients who went on to receive adjuvant therapy had better performance status. When you consider the patients who had induction therapy, and we had a phase II trial that showed that, and Dr Weder from Switzerland also had a trial that showed that, the preliminary results are encouraging: a 23-month median survival in patients who underwent resection, even a 38-month median survival. We have looked at it in the setting of EPP. No one has really looked at induction therapy in the setting of pleurectomy. That is an area still ripe for investigation.

Dr W. Weder (Zurich, Switzerland). The survival curve after the 2 procedures goes more or less in parallel after a few months of surgery. The main difference in survival between the 2 procedures occurs in the early weeks or months, and because the perioperative mortality is almost the same with $3 \%$ and $7 \%$, I would like to know how you explain this. Why is the early survival between the 2 groups so different?

Dr Flores. That is an excellent question, and we looked into that. We performed this same analysis on patients after operative mortality was excluded, and the results were the same. What I think is going on, when you look at the patients with stage IV, the median survival of the extrapleurals is 4 months. I think that is what brings the curve down at the beginning.

Dr R. Bueno (Boston, Mass). You showed us that lymph node status has a major impact on survival in a large cohort of patients with mesothelioma. Did you include the lymph node status in the multivariate analyses and did lymph node positivity affect any of the results?

Dr Flores. We did a multivariable analysis including lymph node status, gender, surgeon, basically those variables, and there was no difference. 


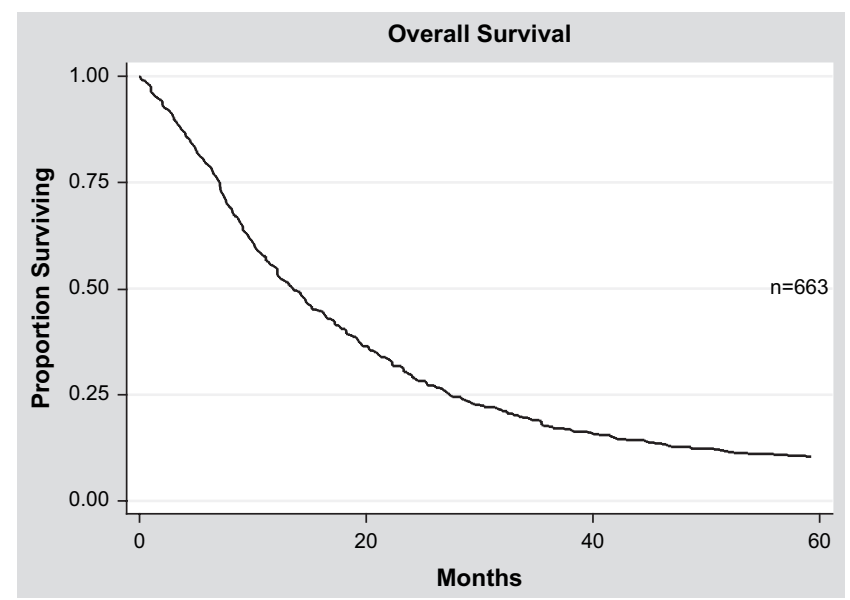

Figure E1. Overall survival of all 663 patients in this study. 
TABLE E1. Clinical characteristics of 663 patients in this study

n (\%)

$\begin{array}{lc}\text { Median age } 63 \text { y (range 26-93 y) } & \\ \text { Men } & 536(81 \%) \\ \text { Women } & 127(19 \%) \\ \text { Laterality } & 390(59 \%) \\ \text { Right } & 273(41 \%) \\ \text { Left } & 380(57 \%) \\ \text { History of asbestos exposure } & \\ \text { Histology } & 447(67 \%) \\ \text { Epithelioid } & 216(33 \%) \\ \text { Non-epithelioid } & \\ \text { AJCC stage } & 52(8 \%) \\ \text { I } & 142(21 \%) \\ \text { II } & 411(62 \%) \\ \text { III } & 58(9 \%) \\ \text { IV } & \\ \text { Surgery } & 385(58 \%) \\ \text { EPP } & 278(42 \%) \\ \text { P/D } & \\ \text { Adjuvant therapy } & 186(28 \%) \\ \text { Chemotherapy* } & 152(23 \%) \\ \text { Radiotherapy } & 89(14 \%) \\ \text { Both } & \end{array}$

$A J C C$, American Joint Committee on Cancer; EPP, extrapleural pneumonectomy; $P / D$, pleurectomy/decortication. *Includes preoperative chemotherapy, postoperative chemotherapy, intrapleural chemotherapy, and tetrathiomolybdate. 
TABLE E2. Postoperative adverse events recorded according to Common Terminology Criteria for Adverse Events 3.0*

\begin{tabular}{|c|c|c|c|c|c|}
\hline \multicolumn{6}{|c|}{ Complications of EPP ( $n=385)$} \\
\hline Complication & Grade 1 (mild) & Grade 2 (moderate) & Grade 3 (severe) & Grade 4 (disabling) & Grade 5 (death) \\
\hline Atrial arrhythmia & & $66(17.1 \%)$ & & & \\
\hline Hemorrhage & & & & 3 & 1 \\
\hline Cardiac herniation & & & & & 1 \\
\hline Deep venous thrombosis & & 3 & & & \\
\hline Empyema & & 2 & & 12 & 1 \\
\hline Gastrointestinal & & 3 & 1 & & 1 \\
\hline Respiratory $\dagger$ & & & $17(4.4 \%)$ & $8(2 \%)$ & $14(3.6 \%)$ \\
\hline Pulmonary embolus & & & & 3 & 3 \\
\hline Multiorgan failure & & & & & 2 \\
\hline Myocardial infarction & & 2 & & & 2 \\
\hline Ventricular arrhythmia & & 2 & & 1 & 2 \\
\hline Urinary tract infection & & 2 & & & \\
\hline
\end{tabular}

\begin{tabular}{|c|c|c|c|c|c|}
\hline \multicolumn{6}{|c|}{ Complications of PD $(n=278)$} \\
\hline Complication & Grade 1 (mild) & Grade 2 (moderate) & Grade 3 (severe) & Grade 4 (disabling) & Grade 5 (death) \\
\hline Atrial arrhythmia & & $13(4.7 \%)$ & & & \\
\hline Hemorrhage & & & & 1 & \\
\hline Deep venous thrombosis & & 1 & & & \\
\hline Gastrointestinal & & & 1 & & \\
\hline Prolonged air leak & $10(3.6 \%)$ & & & & \\
\hline Respiratory $\dagger$ & & & $7(2.5 \%)$ & $1(0.3 \%)$ & $10(3.6 \%)$ \\
\hline Pulmonary embolus & & & & & 1 \\
\hline Multiorgan failure & & & & & 1 \\
\hline Myocardial infarction & & 1 & & & \\
\hline Ventricular arrhythmia & & & & & 1 \\
\hline Urinary tract infection & & 1 & & & \\
\hline
\end{tabular}

EPP, Extrapleural pneumonectomy; $P / D$, pleurectomy/decortication. *CTCAE, National Cancer Institute; Common Terminology Criteria for Adverse Events v.3.0. Available at: http://ctep.cancer.gov/forms/CTCAEv3.pdf). 2006. †Respiratory complications include pneumonia, atelectasis, adult respiratory distress syndrome, and pulmonary edema. 